\title{
ELECTRONIC FRINGE SIGNAL DETECTION CIRCUITRY FOR LENGTH-MEASURING
} INTERFEROMETERS (U)

\section{J. J. Henry}

W. A. Groppe

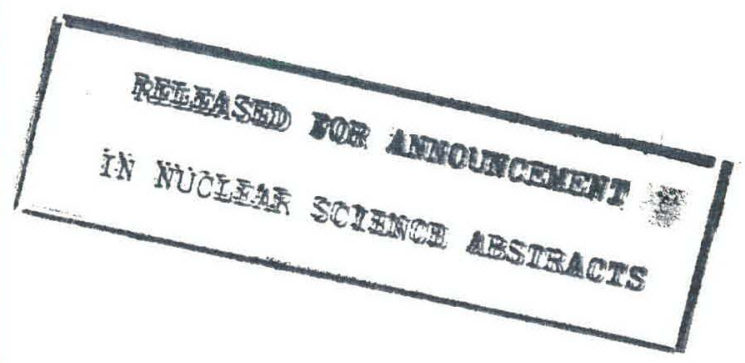

\section{UNION CARBIDE CORPORATION}

NUCLEAR DIVISION OAK RIDGE Y-12 PLANT

operated for the ATOMIC ENERGY COMMISSION under U. S. GOVERNMENT Contract W-7405 eng 26 


\section{DISCLAIMER}

This report was prepared as an account of work sponsored by an agency of the United States Government. Neither the United States Government nor any agency Thereof, nor any of their employees, makes any warranty, express or implied, or assumes any legal liability or responsibility for the accuracy, completeness, or usefulness of any information, apparatus, product, or process disclosed, or represents that its use would not infringe privately owned rights. Reference herein to any specific commercial product, process, or service by trade name, trademark, manufacturer, or otherwise does not necessarily constitute or imply its endorsement, recommendation, or favoring by the United States Government or any agency thereof. The views and opinions of authors expressed herein do not necessarily state or reflect those of the United States Government or any agency thereof. 


\section{DISCLAIMER}

Portions of this document may be illegible in electronic image products. Images are produced from the best available original document. 
Printed in the United States of America. Available from Clearinghouse for Federal Scientific and Technical Information, National Bureau of Standards,

U.S. Department of Commerce, Springfield, Virginia 22151

Price: Printed Copy $\$ 3.00$; Microfiche $\$ 0.65$

\section{LEGAL NOTICE}

This report was prepared as an account of Government sponsored work. Neither the United States, nor the Commission, nor any person acting on behalf of the Commission:

A. Makes any warranty or representation, expressed or implied, with respect to the accuracy, completeness, or usefulness of the information contained in this report, or that the use of any information, apparatus, method, or process disclosed in this report may not infringe privately owned rights; or

B. Assumes any liabilities with respect to the use of, or for damages resulting from the use of any information, apparatus, method, or process disclosed in this report.

As used in the above, "person acting on behalf of the Commission" includes any employee or contractor of the Commission, or employee of such contractor, to the extent that such employee or contractor of the Commission, or employee of such contractor prepares, disseminates, or provides access to, any information pursuant to his employment or contract with the Commission, or his employment with such contractor. 
Date Issued: February 9, 1967

Report Number

$Y-1566$

Engineering and Equipment

TID-4500

CFEII PRICES

r. $\$ 3.00 ; \mathrm{MN} .65$

UNION CARBIDE CORPORATION

Nuclear Division

$$
\text { Y-12 PLANT }
$$

Contract W-7405-eng-26

With the US Atomic Energy Commission

ELECTRONIC FRINGE SIGNAL DETECTION CIRCUITRY FOR

LENGTH-MEASURING INTERFEROMETERS

J. J. Henry
W. A. Groppe

RELEASED BOR ANAOUNCEYEFT

IN NUCLEAF SCIENCE AESTRACTS

\section{LEGAL NOTICE}

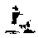

This report was prepared as an account of Government sponsored work. Nelther the United States, nor the Commission, nor any person acting on behalf of the Commission;

A. Makes any warranty or representation, expressed or Implied, with respect to the accuracy, completeness, or usefulness of the information contained in this report, or that the use of any information, apparatus, method, or procese disclosed in this report may not infiringe privately owned rights; or

B. Assumes any liabilitles with respect to the use of, or for damages resulting from the use of any information, apparatus, method, or process disclosed in this report.

As used in the sbove, "person acting on behalf of the Commission" Includes any employee or contractor of the Commisaion, or employee of such contractor, to the extent that such employee or contractor of the Commission, or employee of such contractor prepares, disseminates, or provides access to, any information pursuant to his employment or contract with the Commission, or his employment with such contractor. 
Report Number

$Y-1566$

Engineering and Equipment TID-4500

Distribution:

\begin{tabular}{|c|c|c|}
\hline $\begin{array}{l}\text { Ackerson, R. D. } \\
\text { Bailey, E. W. }\end{array}$ & $\begin{array}{l}\text { Kite, H. T. } \\
\text { McLendon, J. D. }\end{array}$ & \\
\hline Ballenger, H. F. & Meeks, E. J. & $(\mathrm{AFSC})$ \\
\hline Bell, B. B. & Mitchel, G. W. & . \\
\hline Bernander, N. K. & Rader, D. H. & \\
\hline Briscoe, $0 . W$ & Schwenn, M. F. & \\
\hline Burkhart, L.E. & Stoner, H. H. & \\
\hline Center, C. E. & Strasser, G. A. & \\
\hline Christman; A. M. & Trotter, T.C. & . \\
\hline Dutton, Wayne & Waters, J. L. & \\
\hline Evans, G. W. & Wesley, R. L. & \\
\hline Groppe, W: A: & Whitson, W. K. & \\
\hline Harwell, W. L. . ... & Winkel.; R..A... & (Paducah) \\
\hline 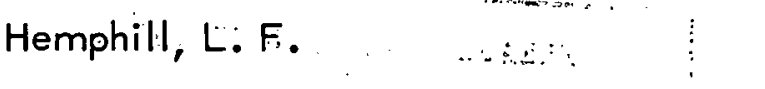 & Wood, D. C. & \\
\hline 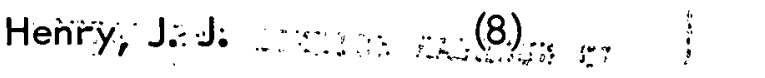 & Yaggi, W. J. & \\
\hline Huber, A.,P & Zurcher, E. & \\
\hline$I M O G$ & Y-12 Central Files & $(60)$ \\
\hline $\begin{array}{l}\text { Jạckson, V.C. } \\
\text { Jennings, D. A. }\end{array}$ & Y-12 Central Files & $(Y-12 R C)$ \\
\hline$(A E C-0 R O)(4)$ & & \\
\hline
\end{tabular}

In addition, this report is distributed in accordance with the category Engineering and Equipment, as given in the "USAEC Standard Distribution Lists for Unclassified Scientific and Technical Reports", TID-4500. 


\title{
RELEASED POR ANENOUNCEMENT \\ IN NUCLEAR SCIENCE ABETRACTS
}

\begin{abstract}
An electronic signal-conditioning system has been designed for use with laser-actuated length-measuring interferometers. Many improvements have been incorporated in this design to provide extended, frequency response, stability, and operator convenience. These improvements allow "shop" use of the interferometer by nontechnical personnel for inspection and machinetool control.

Test results obtained from four prototype systems demonstrate the capability of the design. Maintenance and operating procedures are included for both the electronic and optical systems.
\end{abstract}




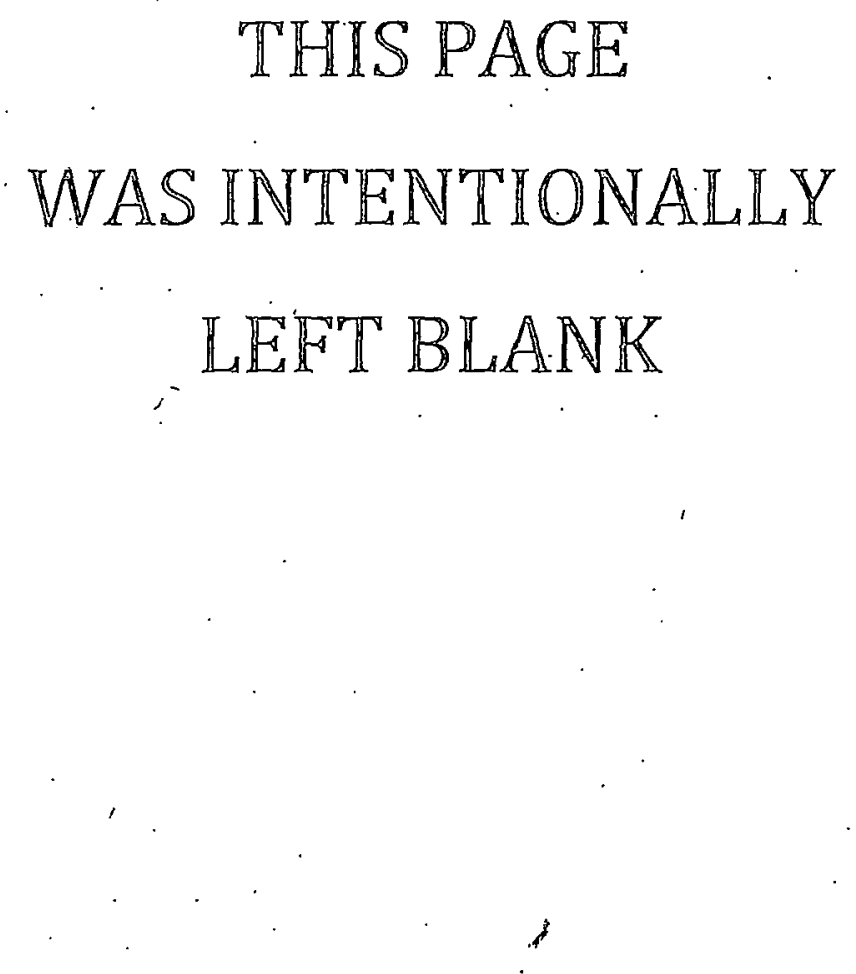




\section{CONTENTS}

SUMMARY .................... 7

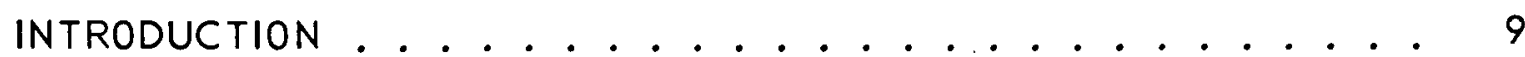

INTERFEROMETER DETECTION CIRCUITRY . . . . . . . . 11

Components ...................... 11

Electronic Circuitry .................. 13

Tests ..................... 16

Criteria ................... 16

Results................... 18

Application. ................. . . 19

ACKNOWLEDGEMENTS .................. 21

REFERENCES ...................... 23

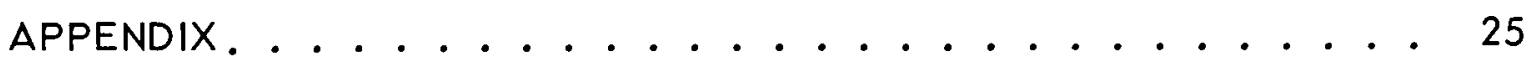

Interferometer Operation, Maintenance, and

Alignment Procedures . . . . . . . 25

Operation. . . . . . . . . . . . . . 25

Maintenance. . . . . . . . . . . . . . 26

Alignment .................. 29 29 


\section{THIS PAGE \\ WAS INTENTIONALLY \\ LEFT BLANK}




\section{SUMMARY}

An interferometer detection system consisting of a detector, preamp, amplifier, and a Schmitt trigger has been developed for use with laser-actuated, lengthmeasuring interferometers. This system has been designed for optimum stability using silicon transistor circuitry and employing a photosensitive field-effect transistor as the interferometer fringe detector. Frequency response in excess of $500 \mathrm{khz}$ can be obtained, and the Schmitt hysteresis can be adjusted to minimize the effect of random noise. The interferometer detector system has been tested in a typical laser interferometer measuring system at translation velocities up to 60 inches per minute, in the presence of noise and vibration, without detectable loss of count. 
THIS PAGE

WAS INTENTIONALLY

LEFT BLANK 


\section{INTRODUCTION}

Although Michelson devised the first length-measuring interferometer near the end of the 19th century, it had remained a laboratory device because of its limited range and the skill required to use it. However, recent development of the gas laser, with its intense, coherent, monochromatic light, and improvements in the mechanical design of the optical system coupled with easily used stable electronic circuitry, have now made the interferometer a practical shop tool. The fruits of the orders-of-magnitude increase in signal thus obtained by using the gas laser have been supplemented by stable and easily maintained electronic signal-conditioning equipment to provide a length-measuring system that provides an extended range and a higher inherent accuracy.

This report specifically describes the electronic signal-conditioning equipment, its application, operation, maintenance, construction, and results of performance tests. The interferometer design associated with this circuitry represents the result of five years of laboratory and field experience, including its installation on several operating machine tools. 
THIS PAGE

WAS INTENTIONALLY

LEFT BLANK 


\section{COMPONENTS}

A length-measuring interferometer $(1,2)$ requires two information channels to determine the direction of motion. The optical package, detectors, and preamps are shown in Figure 1. This entire assembly is referred to as the interferometer. The detector and preamp for Channel $A$ are located opposite

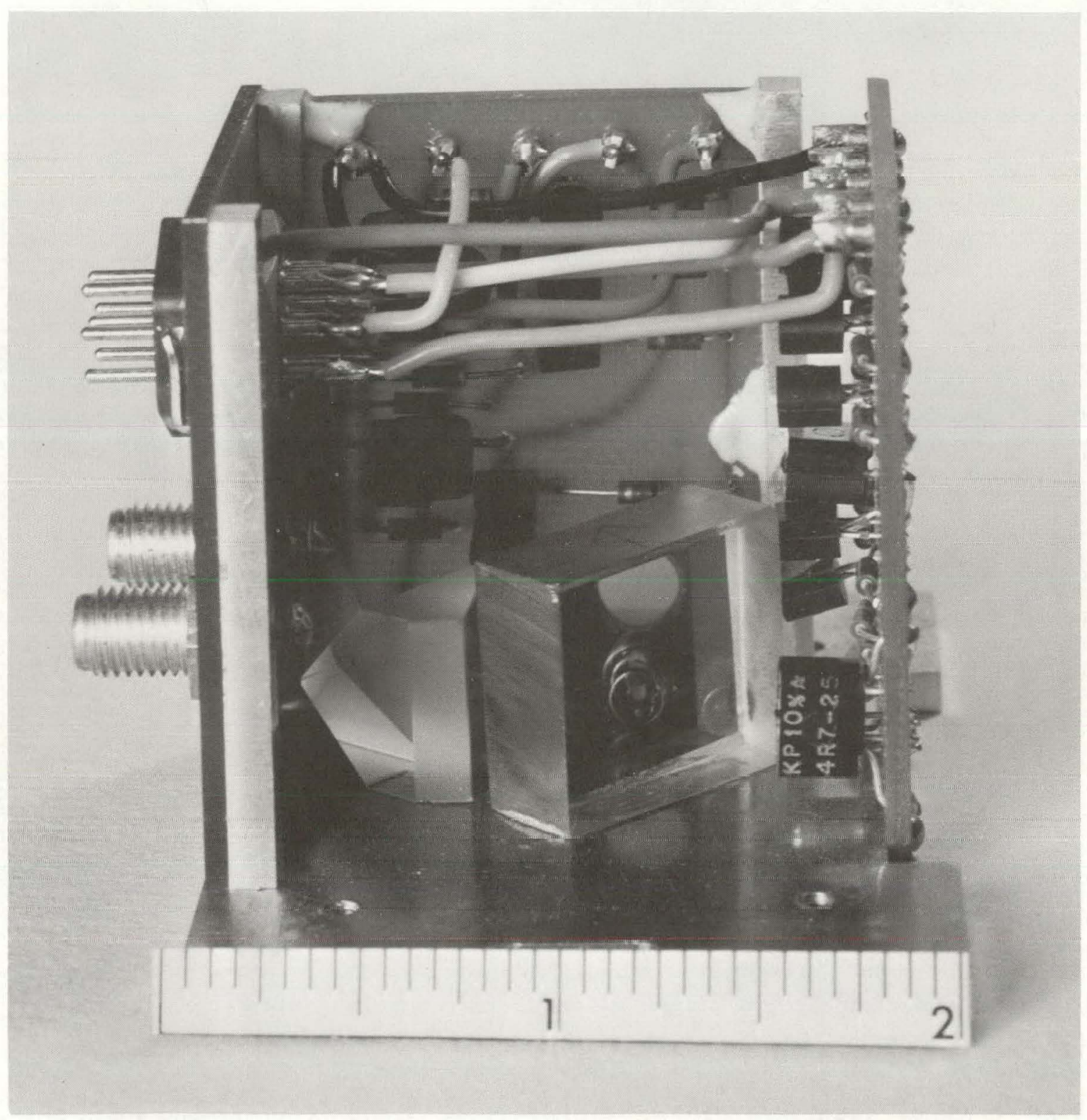

Figure 1. INTERFEROMETER AND PREAMP CIRCUIT BOARDS. 
the connector mounting plate, and at right angles to the plate for Channel B. Figure 2 shows the interferometer from the circuit side of the Channel $B$ printed circuit board and illustrates the location of the cable connectors. Laser light enters the interferometer through the hole near the bottom of the Channel B printed circuit board.

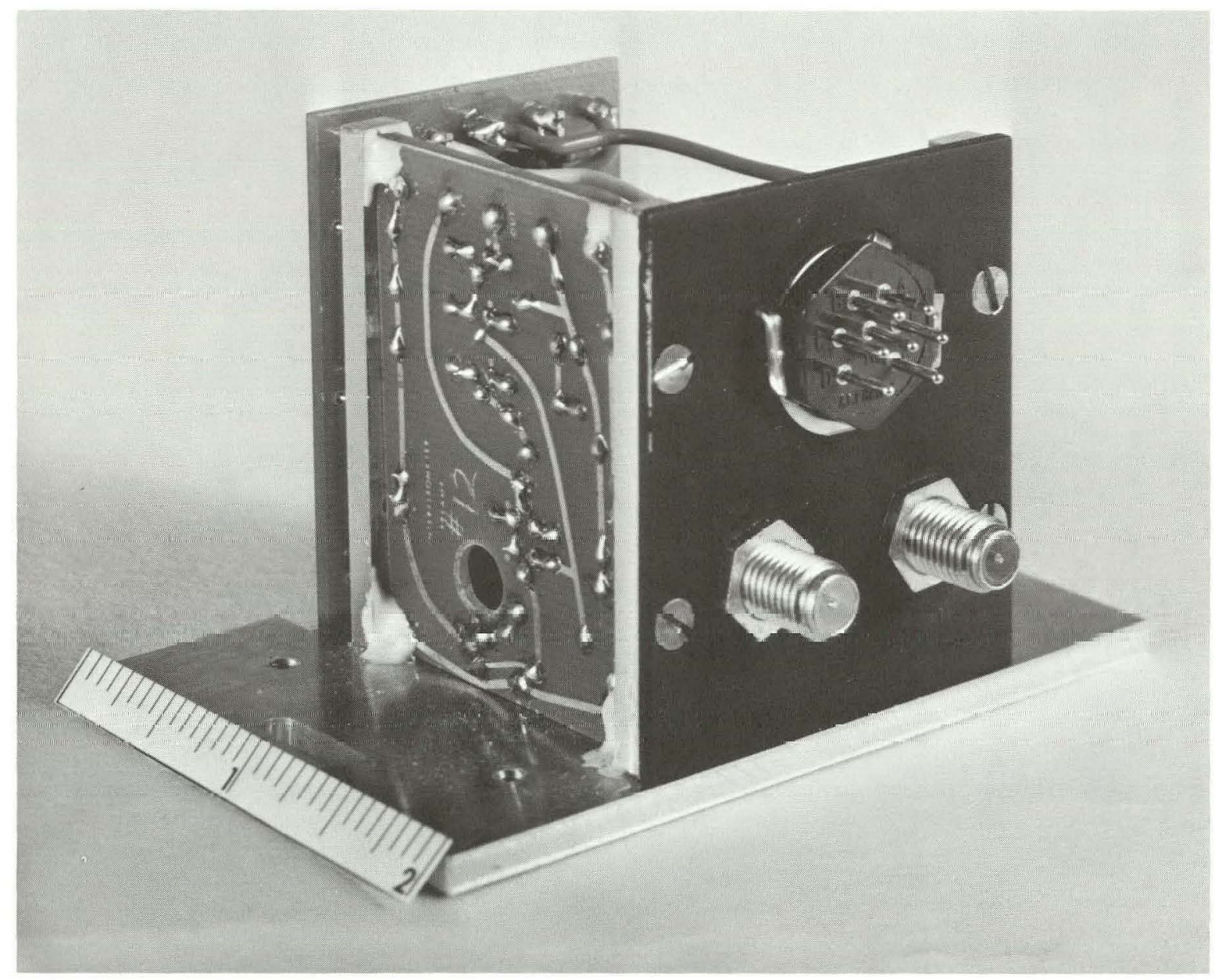

119877

Figure 2. INTERFEROMETER. (Connector View)

The interferometer is mounted on a fixed mount. A movable corner-cube reflector is used to obtain dimensional information. A maximum of 30 feet of interconnecting cable may be used between the interferometer and its associated terminal equipment.

The terminal equipment, shown in Figure 3, consists of a module and bincabinet system, $(3)$ which houses a balance-monitor meter circuit and one to three power and control plug-in modules, each of which is capable of handling 


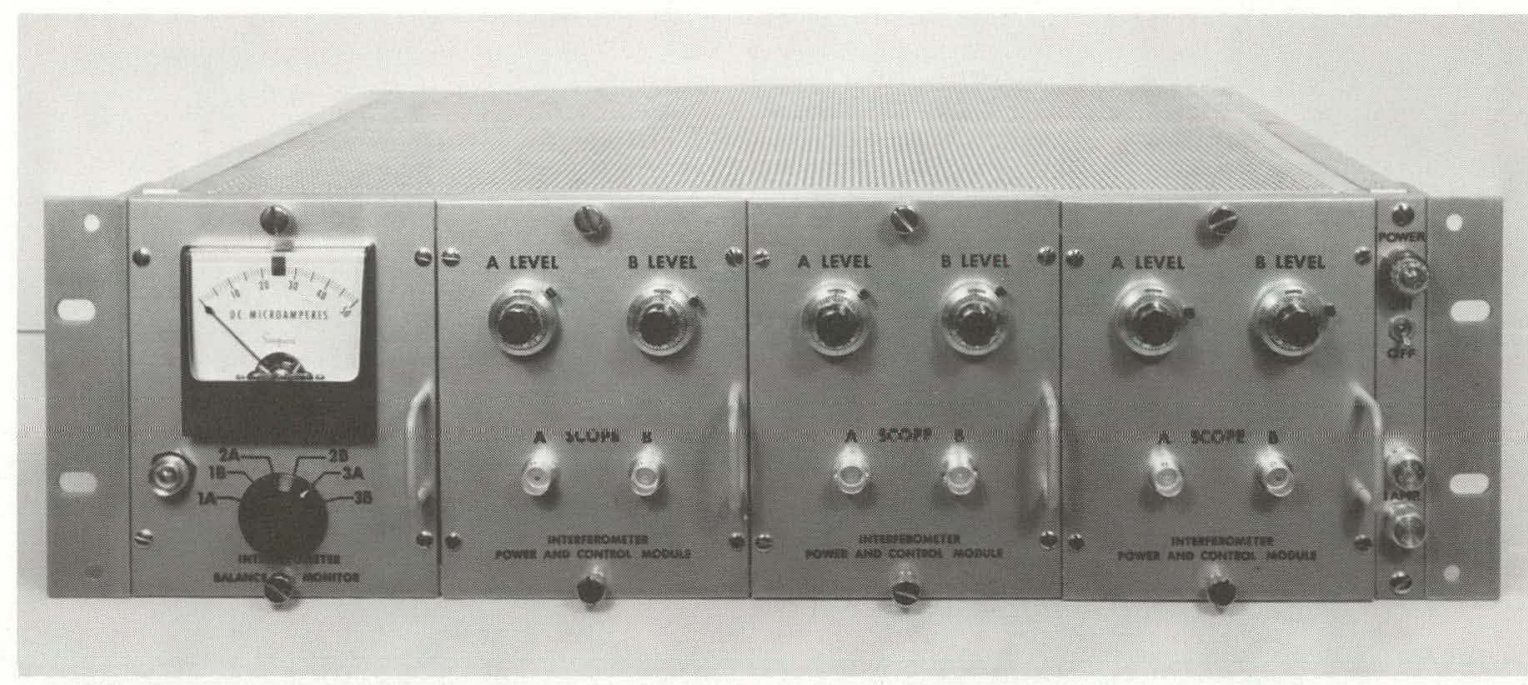

119878

Figure 3. INTERFEROMETER TERMINAL EQUIPMENT. (Module and Bin System)

a single-axis interferometer system. A power and control module is shown in Figure 4, extracted from the bin.

Highly reliable resistors, capacitors, diodes, and silicon transistors are used throughout the electronic system. Epoxy-fiber glass, etched circuit boards are used, and the circuit is coated with chemically deposited tin to reduce corrosion and to improve solderability. Care is taken in the layout so that the critical components and their leads will be arranged in a way that will prevent transient susceptability or thermal interference. Power-supply components and the heat which they generate are kept at a moderate distance from the amplifying circuitry. Adequate ventilation is provided by the perforated top and bottom bin covers.

\section{ELECTRONIC CIRCUITRY}

A block diagram of the electronic circuitry is presented in Figure 5. The fringe detector used is a photosensitive field-effect transistor (Photofet). This type of detector was selected instead of a conventional photodiode, photoconductor, or phototransistor because it provides improved frequency response, increased output signal, and better temperature stability (when properly biased), and still at a comparable cost. The Photofet also allows convenient application of stabilizing DC feedback to the signal source, which can improve gain, drift, and noise characteristics.

Temperature stability of the Photofet is achieved through the selection of a self-biasing resistor $\left(R_{X}\right.$ in Figure 5$)$. This resistor value is selected for 


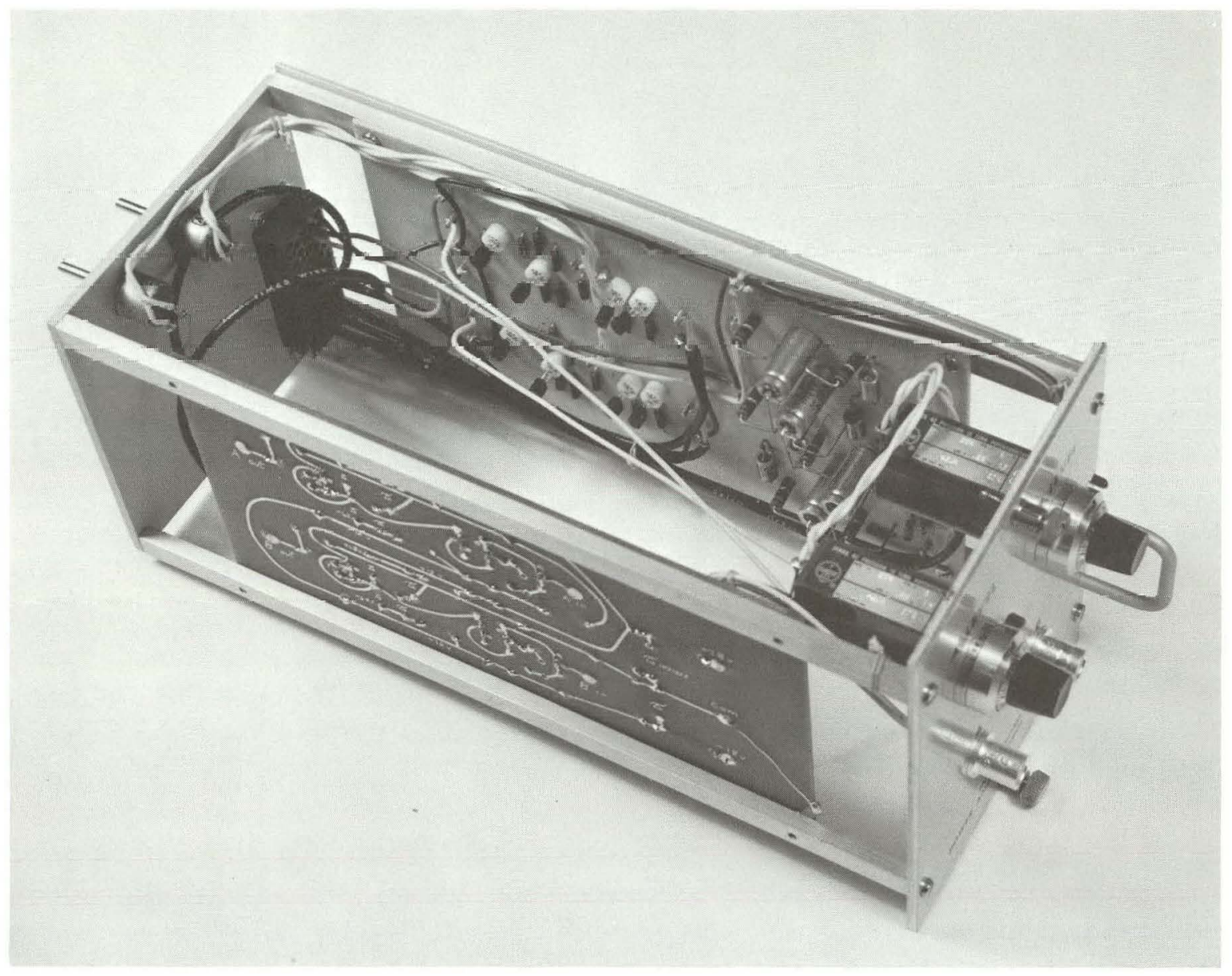

119881

Figure 4. INTERFEROMETER POWER AND CONTROL MODULE.

the individual Photofet characteristics in order to bias the unit for a dark operating voltage, about 0.63 volt above cutoff. The Photofet exhibits a negative temperature coefficient near the cutoff and a positive temperature coefficient near zero bias. A smooth transition in the temperature coefficient occurs, passing through zero near the diode forward voltage above the cutoff voltage (about 0.63 volt in silicon). Biasing in this region insures a good temperature performance.

The Photofet detector for Channel $\mathrm{N}$ is operated in the source-follower configuration in order to degenerate the input capacity and increase the frequency response. The output is balanced against a level-set DC voltage (adjusted at the terminal equipment using the level-set control) at the inputs of the PNP differential amplifier. This level-set control is the only operator adjustment in each signal channel. The output of the first amplifying stage is fed back to the gate of the Photofet to reduce noise, stabilize the gain, and further reduce drift and temperature effects. 


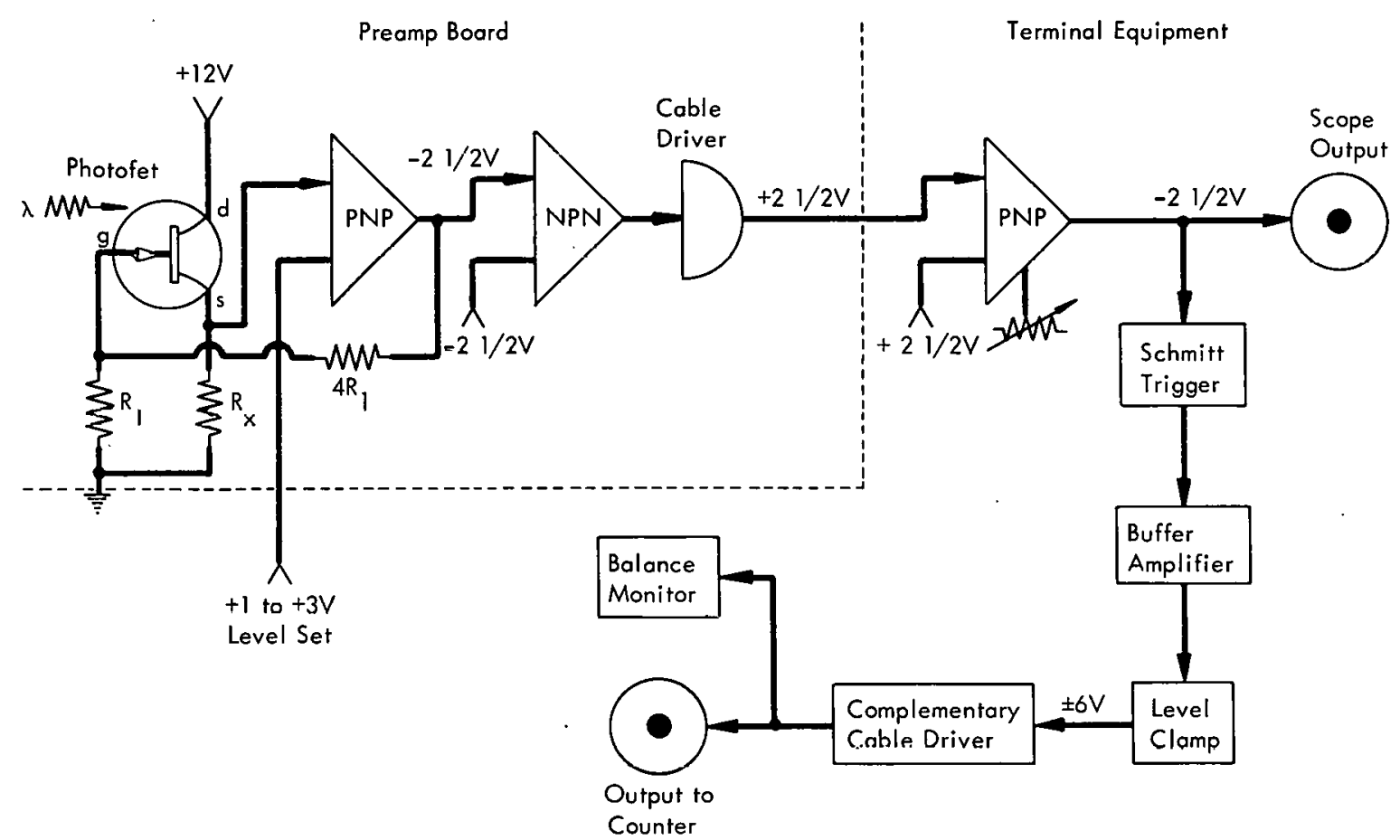

Figure 5. ELECTRONIC CIRCUITRY OF THE INTERFEROMETER FRINGE SIGNAL CHANNEL.

The preamp uses a second differential amplifier stage to further boost the signal level and, thereby, minimize cable noise or other external interference. This step is followed by an emitter-follower circuit designed to drive up to 30 feet of RG-174/U or RG-58/U coaxial signal cable. The differential amplifier circuit configuration is used throughout this design for linear amplification, as it provides automatic temperature compensation, good frequency response (when used with low values of resistance), and stable gain. Alternate use of PNP and NPN transistor differential-amplifier stages permits direct coupling without level-shifting networks, as the required voltage offsets are easily incorporated into the design.

The terminal equipment houses raw power supplies, Zener regulators, and the remaining electronic system shown in Figure 5. Separate raw power supplies are provided for each interferometer control module, and separate Zener regulators are used for each signal channel in order to eliminate "cross talk" or mutual interference between circuits.

In the terminal equipment, the signal is first applied to a differential amplifier with an adjustable gain. Normally, the gain of this amplifier is set so that the system noise (with the Photofet dark) is less than one half the Schmitt hysteresis, or 0.4 volt peak-to-peak at the oscilloscope output connector. 
When both channels have been adjusted for the maximum usable system gain with the photocells dark, the channel having the larger signal may be reduced until the output signals (from fringes) are approximately equal in amplitude. Occasionally, on a very intense laser, it may be necessary to reduce both channels in order to prevent distortion in the output.

The variable-gain stage is followed by a Schmitt trigger operating in the - 2 to - 3-volt level with a 0.8 -volt hysteresis. The Schmitt output is amplified and clamped (at either $a-6$ or +6 -volt nominal level), then it actuates a complementary transistor cable driver. This form of cable driver supplies a low impedance drive for fast transients in both directions into a moderatecapacity load. If the associated counter requires a negative signal, a diode blocking circuit can be used to provide a 0 to - 6-volt signal; if a positive signal is required, the diode may be reversed for a 0 to +6 -volt signal; if a bipolar signal of lesser amplitude is required, a simple attenuator may be used. Since these additions should be added at the load end of the output cable to prevent the slow down of the cable driver's response, they are not included in the design.

A balance monitor is also provided in the terminal equipment. By means of a selector switch, the operator. can monitor any one of the six signal channels and adjust the level. for optimum performance. When the machine is moving and fringes are moving by the fringe detector, the monitor meter indicates the duty cycle of the Schmitt output in the selected channel. When the duty. cycle of the positive and negative: portions of the Schmitt output are equal, the monitor meter indicates. 50: percent of full scale (which is the desired condition), and the individual channel level control may be readily adjusted to balance the duty cycle. The separate power-supply regulators on each signal channel were found to be necessary to prevent interaction between the level controls. While this level control is the only one normally intended for operator use, and adequate adjustment of it may be readily made using the balance monitor, the use of oscilloscope patterns and other test equipment may be helpful for alignment or trouble shooting.

Detailed operating, maintenance, and alignment procedures are given in the Appendix.

\section{TESTS}

Criteria

To derive optimum utility from this circuitry, the following design criteria were established: 
1. The DC drift of the detector and amplifier circuitry should be insignificant when compared to the normal interferometer fringe-signal amplitude. The normal signal from a two-axis laser-interferometer system was determined experimentally to be about 5 to 20 times as much as normal room light (normal room light is about $80 \mu \mathrm{w} / \mathrm{cm}^{2}$ ). From this measurement, the lowest acceptable interferometer signal amplitude was determined to be four times room light; hence, room light was 25 percent of the minimum acceptable interferometer light level. Drift rate on each detector and preamp is then referenced to the minimum interferometer signal by comparing the dark output level changes with the output level change which occurs when the detector is exposed to room light.

2. The frequency response of the linear portion of the system should be flat from DC to a frequency high enough to minimize the effects of shock, vibration, and differential high-frequency phase shift upon the operation of the counter. The desired system bandwidth was computed using the frequency modulation (FM) theory ${ }^{(4)}$ for the case of translation at 60 inches per minute with simultaneous vibration of differential amplitude, 250 microinches peak-to-peak, at a frequency of one kilohertz. This bandwidth was found to be in excess of $140 \mathrm{khz}$. If a linear response to $140 \mathrm{khz}$ with low differential phase shift is realized, the required 3-decibel bandwidth must be a factor of two or three times as wide. For this reason, a-3-decibel response from DC to $500 \mathrm{khz}$ is desirable. To test the optical system at frequencies exceeding about $30 \mathrm{khz}$, it is necessary to either mount it on an interferometer on a rapidly traversing slide, or supply a source of amplitude uncluluted (AM) light. A gallium arsenide, light-emitting diode, which can be modulated at frequencies up to (and possibly exceeding) one megahertz, was obtained. This light source, operated by a standard signal generator, is used to measure the frequency response of the system.

3. The interferometer preamp and glassware should be stable under shock or vibration. To test this, the interferometer, while properly adjusted, is operated in the presence of artifically induced shock or vibration using a fast bidirectional counter.

4. The system should show minimum susceptability to interference and line transients. In order to test this condition, the unit is operated in a static condition with a soldering gun, portable drill, or other source of line interference plugged into the same raw power (117 VAC). The counter is observed while the interfering source is turned on and off. The laser may be turned off during this test, eliminating the counts due to fringes, but the DC level at the scope-output connectors should be adjusted to $-21 / 2$ volts to ensure that the entire system is "live" and is as susceptable 
to transient noise as it would be during normal operation. This adjustment can be made using the level-set potentiometer.

\section{$\underline{\text { Results }}$}

The four interferometers already fabricated have been tested in accordance with these requirements. They were further tested to ensure that the design values of the Schmitt hysteresis and transit times have been met. Results of these tests are reported in Table 1.

Table 1

INTERFEROMETER TES.T RESULTS

\begin{tabular}{|c|c|c|c|c|c|c|}
\hline \multicolumn{3}{|c|}{ Interferometer } & \multirow{2}{*}{$\begin{array}{c}\text { Drift(2) } \\
(\%)\end{array}$} & \multirow{2}{*}{$\begin{array}{c}\text { Control Module } \\
\text { Hysteresis } \\
(v)^{\circ}\end{array}$} & \multicolumn{2}{|c|}{ System } \\
\hline Number & Channel & $\begin{array}{c}F_{c o}(1) \\
(k h z)\end{array}$ & & & Shock (3) & Interference \\
\hline \multirow{2}{*}{1} & $A$ & 780 & 3 & 0.85 & \multirow{2}{*}{ OK } & \multirow{2}{*}{ OK } \\
\hline & $B$ & 1000 & 4 & 0.80 & & \\
\hline \multirow{2}{*}{2} & $A$ & 590 & 4 & 0.90 & \multirow{2}{*}{ OK } & \multirow{2}{*}{ OK } \\
\hline & B & 680 & 3 & 0.75 & & \\
\hline \multirow{2}{*}{3} & $A$ & 750. & 2 & $\because 0.80$ & & \multirow{2}{*}{ OK } \\
\hline & B & 820 & 4 & 0.75 & & \\
\hline \multirow{2}{*}{4} & $A$ & 930 & 2 & 0.75 & & \multirow{2}{*}{ OK } \\
\hline & B & 850 & 4 & 0.85 & . & \\
\hline
\end{tabular}

(1) $F_{c o}$ is the 3-decibel upper frequency response of the entire detector and amplifier system as measured with a gallium arsenide light source.

(2) Drift values are given in percent of minimum normal fringe peak-to-peak amplitude and are measured for a 24-hour period.

(3) Interferometers are certified to have passed shock or electrical interference OK if no counts attributable to these sources are observed. Units 3 and 4 have not been shock tested yet.

Since the DC bias on the Photofet is a determinant of the overall temperature performance, the cutoff voltage and zero-bias current of the Photofet for Interferometer I, Channel A, was remeasured after four months of operation. The initially measured cutoff voltage was 2.73 volts, and the zero-bias current

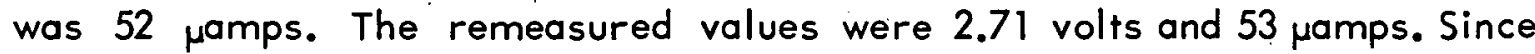
these values are not significantly different, they would still require the same value of the biasing resistor; hence, the values indicate that the performance had not changed substantially in four months of operation. 


\section{APPLICATION}

The circuitry of this interferometer is designed for wide application in lengthmeasuring interferometry. The more exacting criteria placed on its design are that it should slant toward use on inspection machines and machine-tool measurements that are operated by nonscientific personnel. These requirements do not detract from its usefulness in the laboratory and in standard laboratory applications where simplicity of operation and speed may also be attractive.

In order to apply this circuitry to laser-actuated length-measuring interferometers, it is necessary to add a laser; a moving slide or other single-axis motion, with a corner cube mounted for each desired measurement axis (up to 3); suitable mirrors and hardware to align the laser beam with the interferometers and the axis motion; and a standard bidirectional electronic counter for each axis. With these units, this system can be readily applied to length measurements that require a high degree of accuracy. 
THIS PAGE

WAS INTENTIONALLY

LEFT BLANK 


\section{ACKNOWLEDGEMENTS}

The work and assistance of H. S. Corey, C. M. Lay, R. W. Schede, R. E. Sladky, and many others have contributed significantly to this study. 


\section{THIS PAGE \\ WAS INTENTIONALLY \\ LEFT BLANK}




\section{REFERENCES}

(1) Corey, H. S., et al; Length-Measuring Laser Interferometer, $Y-1466$; Union Carbide Corporation-Nuclear Division, Y-12 Plant, Oak Ridge, Tennessee; September 18, 1964.

(2) Frank, N. H.; Introduction to Electricity and Optics, Chapter XVI; McGrawHill, New York, New York (1940).

(3) Standard Nuclear Instrument Modules, Louis Costrell, ed, TID-20893; Atomic Energy Commission, Washington, DC; July 1964.

(4) Terman, F. E.; Radio Engineers Handbook, P 581; McGraw-Hill Book Company, New York, New York (1943). 
THIS PAGE

WAS INTENTIONALLY

LEFT BLANK 


\section{APPENDIX} INTERFEROMETER OPERATION, MAINTENANCE, AND ALIGNMENT PRO-
CEDURES

\section{Operation}

The operation of the interferometer detector and signal-conditioning circuitry has been simplified as much as possible to eliminate complicated setup procedures. A single operator control (called a level set) is provided for each signal channel in order to adjust for the interferometer light intensity. There are two of these controls located on the front panel of each power and control plug-in module-one for each signal channel of the interferometer axis. If the laser is operating and is properly aligned, this adjustment is the only one normally used in operation. Proper adjustment will provide balanced outputs from the Schmitt triggers when the slide is moving. Hence, if the adjustment cannot readily be made, some part of the system has failed, and maintenance is required.

To make the adjustment, start the slide moving slowly so that fringe signals are present. Select the proper fringe signal channel using the rotary selector switch under the balance monitor meter located in the left hand plug-in module of the terminal equipment (Figure $A-1$ ). Rotate the associated level-set adjustment potentiometer until the balance-monitor meter reads inside the greencolored region near 50 percent of full scale. When both signal channels on an interferometer are properly adjusted, the bidirectional counter should count up for one direction of slide motion and down when the motion reverses.

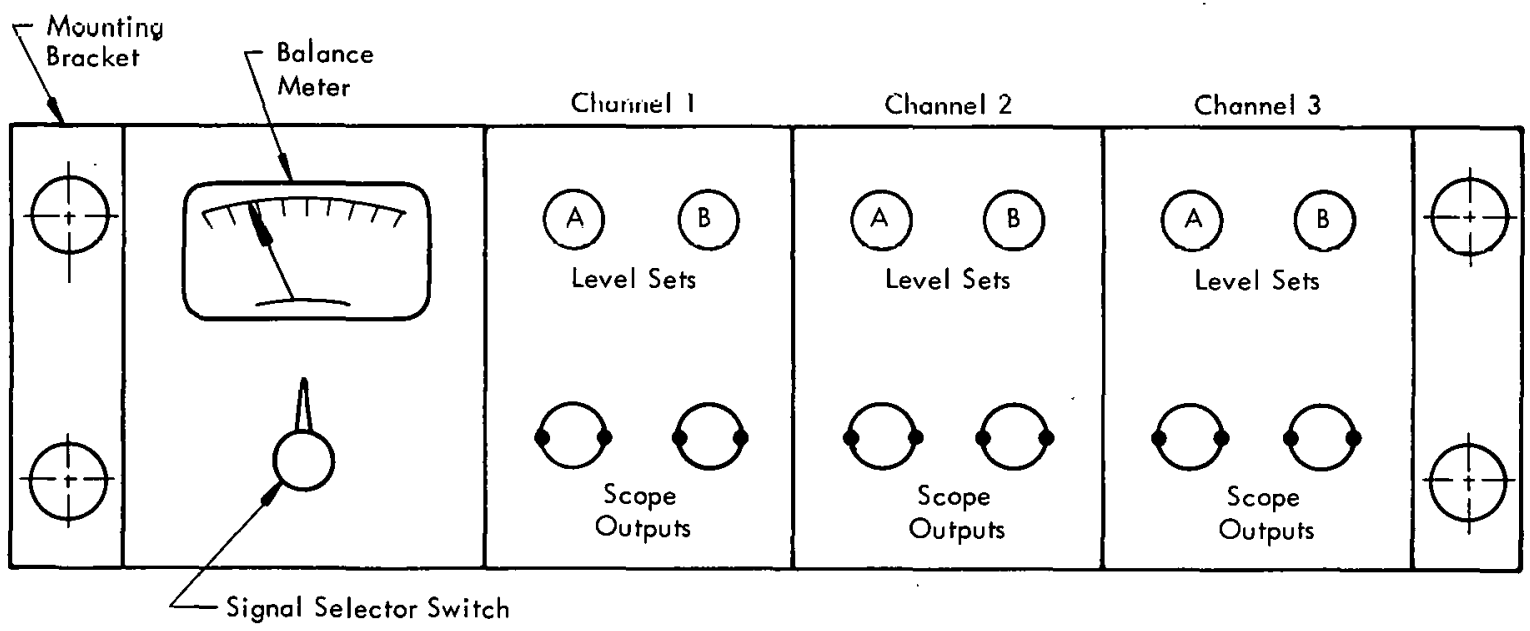

Figure A-1. TERMINAL EQUIPMENT. (Operation Control Diagram) 
The operator may reasonably be expected to make adjustment to the laser tuning and the bidirectional counter; but, since these adjustments depend upon the particular laser and counter used, they are beyond the scope of this report.

\section{MAINTENANCE}

Whenever maintenance is required, the following procedure may be used to isolate the trouble: (Note: Before beginning the troubleshooting operations, determine that all the cables are properly connected and that all units are turned on. Determine that the laser is on by placing a small piece of paper or index card in the beam path. Caution: A laser beam must be observed by reflected light. Do not look directly into the lasers as damage to the eyes may occur.)

If all units look normal and the laser light is present, start the machine slide moving slowly so that fringes are moving past the detector, and attempt to make the balance adjustment. To adjust the balance, select the desired interferometer channel using the rotary switch under the balance meter on the terminal equipment and (with the slide moving) rotate the associated level-set potentiometer until the meter reads inside the green region at mid scale. If the laser is on and adjustment cannot be made, then the trouble is somewhere in the interferometer or the terminal equipment. If the balance adjustment is correct on both channels of the failing unit, then the trouble is in the bidirectional counter or other peripheral equipment and not in the interferometer signal circuitry.

When the trouble has been localized to the interferometer and terminal equipment, it may be further localized through the use of an oscilloscope with a DC-coupled, vertical amplifier. First, remove the input coaxial connectors located at the rear of the bin, but do not disconnect the interferometer power cable (the seven-pin hexagonal connector). The balance meter should now read near full scale on the affected signal channels. If it does read full scale, short out the input connector on the rear of the bin (the one on the bin, not the one on the cable), and observe the balance monitor. If it now reads zero, the trouble is probably in the interferometer; if it still reads near full scale, the trouble is in the terminal equipment.

To further locate the trouble, connect the interferometer signal coaxial cable to the oscilloscope at a sensitivity setting of about one volt per centimeter. With the laser on and the slide moving, attempt to center the trace at about a $+2.5-v o l t-D C$ level, using the level set. Note that the Channel A coaxial connector should have red paint on it, while the Channel $B$ connector is unpainted. Use the A level with the Channel A and the B level with the Channel B. If the signal cannot be set to +2.5 volts (but stays below 0 or above +5 volts), then 
there is trouble in the interferometer, and it should be replaced. If the unit can be set but shows no sign of fringes, remove the interferometer cover and, using a small piece of paper, verify that the interferometer beams enter the photodetectors. If they do not enter, realign the interferometer and the movable corner cube with the laser beam. Normally, it is not possible to adjust the interferometer signal-channel output to a $D C$ level of +2.5 volts unless the detector and preamp for that signal channel are working properly.

If the interferometer signal outputs show fringes of at least one volt peakto-peak amplitude, adjustable to a $D C$ level of +2.5 volts, the trouble must be in the terminal equipment. Remove the shorts on the input connectors and reconnect the input-signal cables. Connect the oscilloscope vertical input to the scope connector on the front of the power and control plug-in module. These outputs should show fringes present and at least two volts peak-to-peak amplitude around a DC level of -2.5 volts. If the fringes are low in amplitude, increase the gain control located on the rear of the plug-in module, providing enough signal is present within the limits described previously for the electronic circuitry. Now, if the unit cannot be adjusted to obtain proper balance, replace the power and control module and recheck the operation with the new module.

The oscilloscope waveforms of Figures A-2 and A-3 should be helpful in locating the failing component whenever trouble occurs in the unit. The power and control plug-in module may be readily tested without an interferometer by jumping one of the level-set potentiometer's outputs (Pin $E$ for the Channel $A$ level-set pot; Pin D for Channel B) on the hexagonal preamp power connector located at the rear of the bin to the appropriate BNC input connector. The level set can then be used as a DC signal level to operate the amplifier and Schmitt trigger circuit. An AC signal can be capacitively coupled into the same point, and the module brought out on an extender cable (or the bin cover removed) to allow access to the circuit for testing. The level-set and amplifier-gain controls should be adjusted to provide a DC level of -2.5 volts at the oscilloscope ("scope") coaxial connector. The output level should go negative when the signal at the scope connector becomes more negative than $-2.9 \pm 0.1$ volts and remain negative until the signal becomes more positive than $-2.1 \pm 0.1$ volts; whereupon, it will become positive. This action may be observed using the $X-Y$ oscilloscope presentation techniques by connecting a signal generator to the amplifier input (rear of the bin), connecting the horizontal axis of the scope to the scope connector on the front of the module, and connecting the vertical axis of the oscilloscope to the output connector at the rear of the bin. A typical Schmitt trigger pattern is shown in Figure A-2.

A lissajous pattern of the amplifier outputs is often helpful in aligning the interferometer and detecting differential phase shift or other troubles. In order 


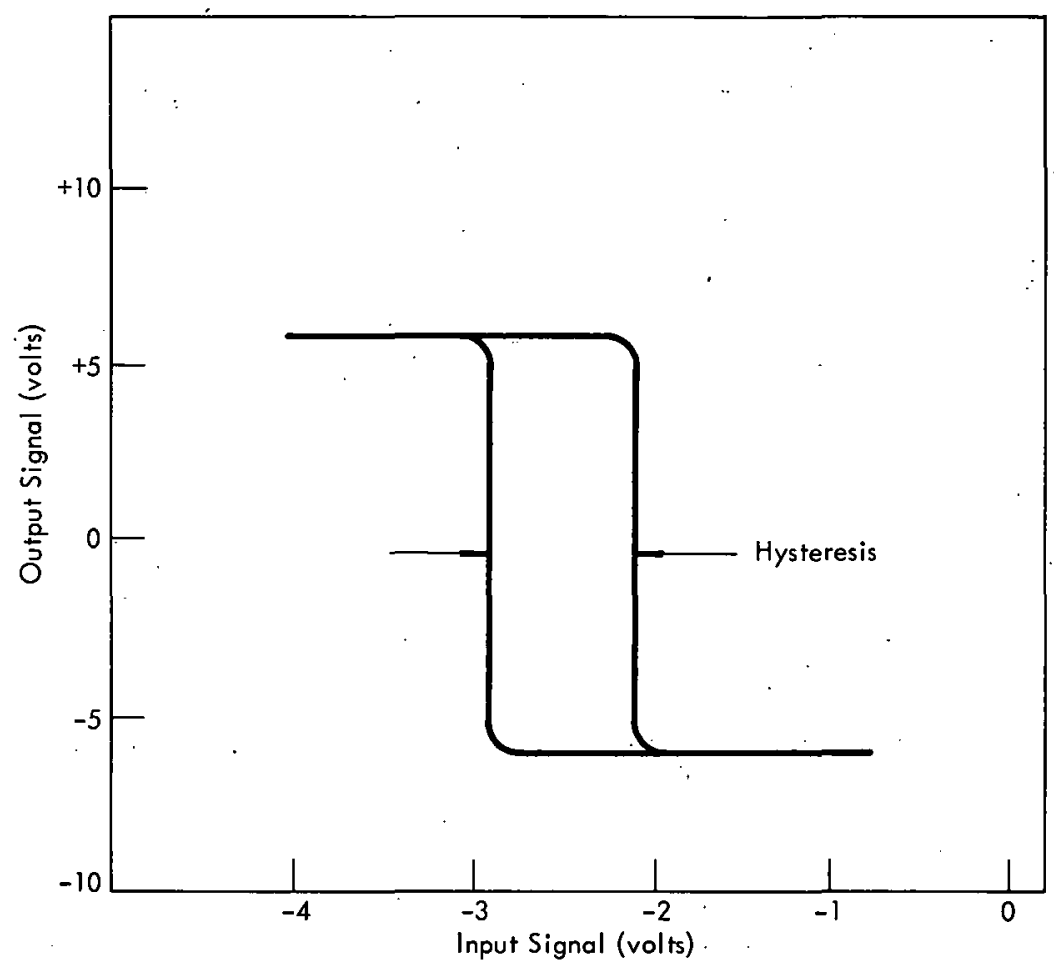

Figure A-2. X-Y OSCILLOSCOPE PRESENTATION OF SCHMITT CHARACTERISTICS.

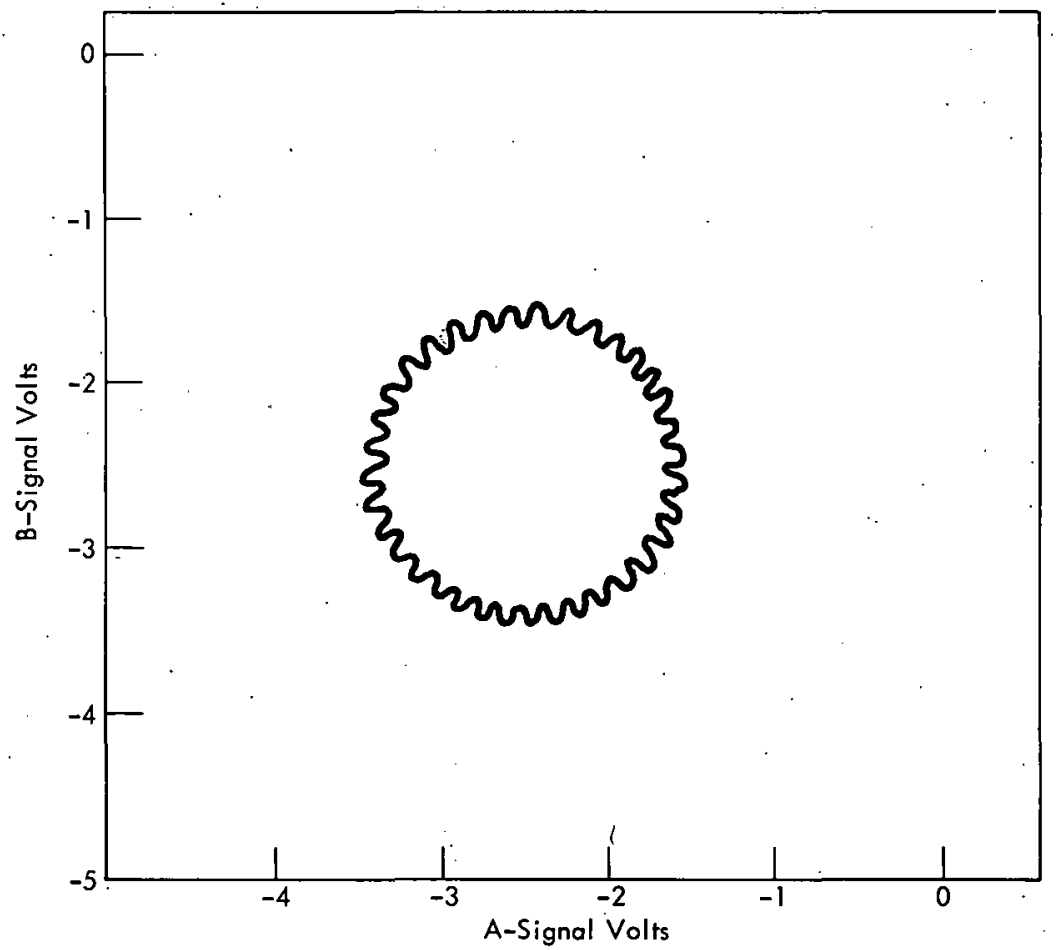

Figure A-3. OSCILLOSCOPE LISSAJOUS PRESENTATION OF INTER. FEROMETER SIGNALS PROPERLY BALANCED AND PHASED. 
NUCLEAR DIVISION

P. O. BOX Y, OAK RIOGE, TENNESSEE 37830

To Recipients of Report Y-1566:

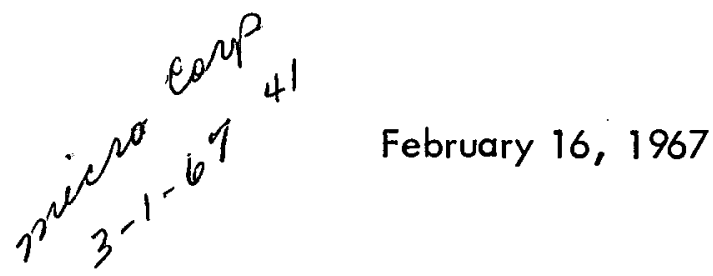

An error exists in Figure A-4, Page 29, of the subject report. The correct figure is reproduced below. Please make the proper correction.

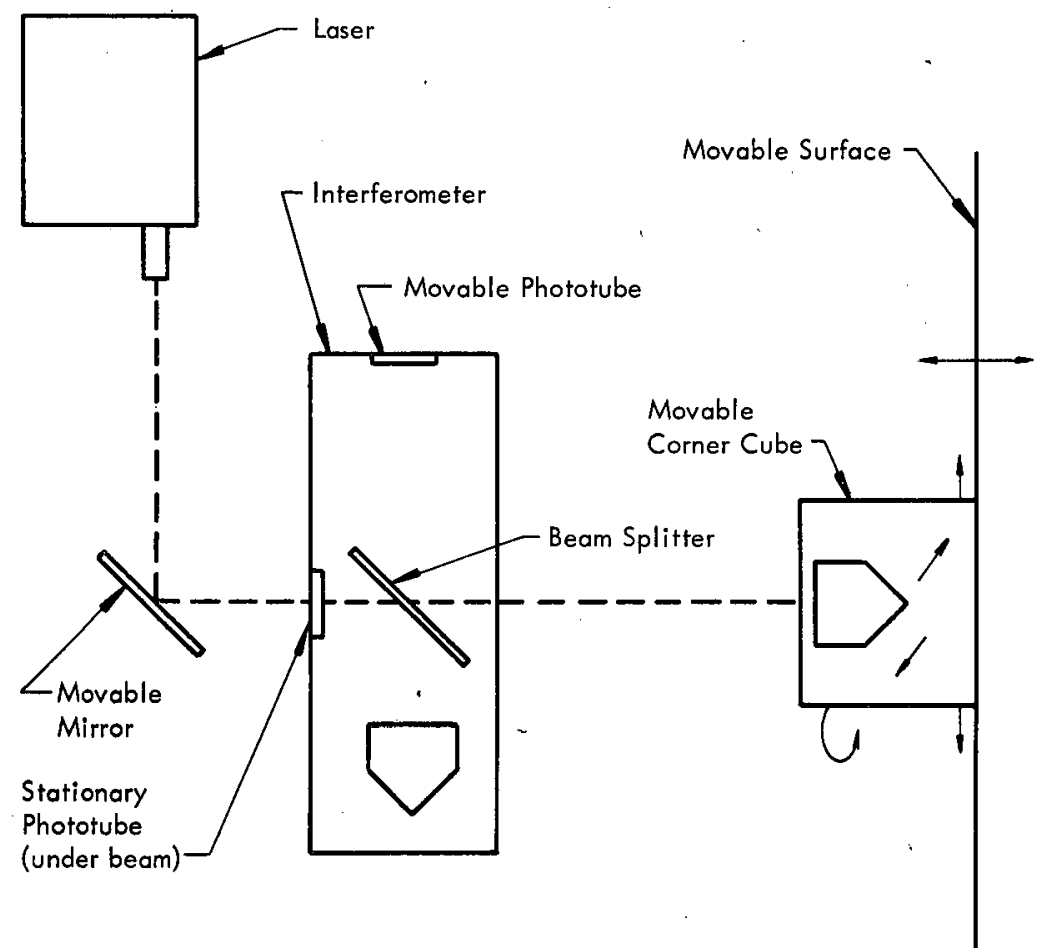

Figure A-4. INTERFEROMETER ALIGNMENT.

Technical Publications

Y-1 2 Plant 
to obtain one (with the interferometer connected, the laser on, and the slide in motion), connect the A-scope output to the oscilloscope horizontal channel and the B-scope output to the oscilloscope vertical channel. Adjust the oscilloscope so that 0,0 volts is positioned in the upper right hand corner of the scope face. The signal should be a nearly round pattern centered around - 2.5, - 2.5 volts, as shown in Figure A-3. Deviation from roundness may be diagnosed as either unequal amplitude or improper phase angle. For example, a vertical ellipse would indicate a weak Channel A (or a strong Channel B), while a diagonal ellipse would indicate other than a 90-degree phase difference between the two signals.

\section{Alignment}

Interferometer Alignment on a Machine - When initially aligning a laser interferometer measuring system on a machine, the use of a mirror between the laser and interferometer enables the beam to be aligned without moving the laser (Figure A-4).

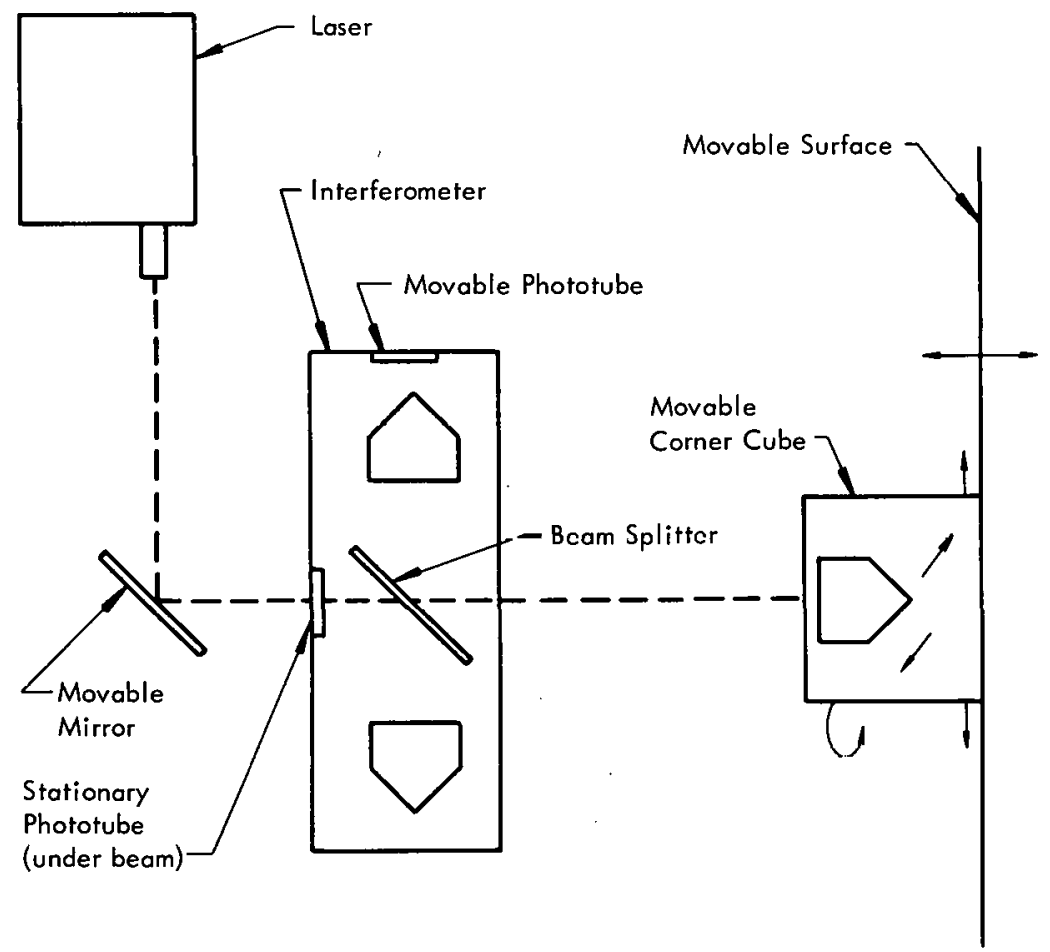

Figure A-4. INTERFEROMETER ALIGNMENT.

Initial alignment of the movable corner cube is more easily accomplished without the interferometer in the beam path. Place a piece of tape with a cross (+) marked on it on the movable surface where the beam spot falls. Starting with the movable surface close to the mirror, align the tape so that the spot falls on the center of the cross. Run the movable surface away from 
the mirror to the most distant point. The spot will probably move with respect to the cross. If it does move, align the mirror so the spot falls in the opposite quadrant, about the same distance from the center. Return the movable surface close to the mirror and move the center of the cross to the beam spot. Repeat until the spot remains stationary as the movable slide is moved from end to end. Replace the tape with the corner cube and put the tape over it so that the laser-beam spot falls on the cross. This step should be done with the movable surface as close to the mirror as possible. Run the surface away from the mirror. The spot will probably move on the cross. Align as previously described except move the corner cube instead of the mirror.

To align the interferometer, cover the corner cube so there is no reflection of the beam from it. Install the interferometer in the beam path so that it does not move with respect to the laser and the mirror when the movable surface is traveling. There are two photodetectors on the interferometerone is stationary just below the initial laser beam, the other is movable (slightly) and off to the side of the beam. Place the interferometer so the beam reflected from the internal corner cube falls on the photodetector. This step can be accomplished by visual inspection or by placing a piece of paper over the photodetector. Uncover the movable corner cube and the reflected beam should fall on the same photodetector. This beam can best be seen by looking at the photodetector output fringe pattern with an oscilloscope. With the movable surface traveling slowly, adjust the movable corner cube for the maximum fringe pattern (sine wave). Here, it is usually a good idea to check the calibration of the laser wavelength. This check is made by turning the wavelength knob on the laser power supply and setting it for a slight valley between two peaks in the observed fringe amplitude. Both beams should now be falling upon the adjustable photodetector. If they are not, adjust it until they visually fall upon it. Critical adjustment of the movable photodetector and movable corner cube can be done by watching a lissajous pattern of the two photodetector outputs. If the fringe amplitudes are equal, the lissajous pattern will approach a circle. Adjustment of the interferometer and movable corner cube should always be for the maximum sine wave or lissajous pattern.

Watch the oscilloscope for DC drift as the movable surface travels. If there is drift, the system is not aligned perfectly.

There are three ways to set the signal controls:

1. Adjust the knob (there is only one for each channel) until the counter just starts counting, and then continue turning the knob in the same direction until the counter stops. Half way between the two points is the proper setting. 
2. Watching the Schmitt trigger output, adjust the knob for a square wave.

3. Watching the lissajous pattern for Schmitt hysteresis (Figure A-2), adjust for equal tip amplitudes outside the hysteresis rectangle so that the fringe signal is balanced on the Schmitt hysteresis.

Realigning the Interferometer - Normally, the movable corner cube is the portion of the system which is misaligned by such problems as bumping and loose screws. Therefore, before checking the interferometer itself, check the corner-cube alignment by placing a piece of tape with a cross $(+)$ on it over the corner cube. With the movable slide close to the interferometer, place the cross so the laser beam spot falls in the center. Move the corner cube away from the interferometer. If the spot has moved from the center of the cross, move the corner cube and place the spot in the opposite quadrant, about the same distance from the center. Move the corner cube back to the start (near the interferometer). Move the tape so the spot now falls on the center of the cross. Repeat until the spot does not move. Final adjustment of the corner cube is made watching the lissajous pattern of both photodetectors. Align the corner cube for the maximum deflection. The shape will be an ellipse or circle if the level set and gain controls are properly adjusted (Figure A-3).

If the pattern is not correct, adjust the laser power supply wavelength control for a slight valley between two peaks on the deflection of the lissajous pattern. If the pattern still is not correct, and good counting is not present over the full range of travel, the interferometer must be adjusted using the same procedure as used in the initial alignment. 